\title{
Analytical modelling of bond-slip failure between epoxy bonded FRP and concrete substrate
}

\author{
Levingshan Augusthus Nelson \\ School of Science, Engineering and Environment, University of Salford, United Kingdom \\ Mustafa Al-Allaf \\ Department of Civil Engineering, Al-Nahrain University, Iraq \\ Laurence Weekes \\ School of Science, Engineering and Environment, University of Salford, United Kingdom
}

\begin{abstract}
In this paper, a set of explicit theoretical derivations from a generalised bond-slip model for an epoxy bonded fibre reinforced polymer (FRP) sheet to concrete are presented. The derivations address the maximum bond resistance, load-slip response, effective bond length and stress-strain distributions along the FRP. The generalised bond-slip model was compared with the existing bond-slip models to obtain the optimal bond-slip parameter using bond resistance results of single and double lap shear tests results available in the literature. The theoretical predictions using the optimal bond-slip parameters showed good agreement with experimental results of double lap shear tests. Furthermore, in order to understand the influence of the bond-slip parameters, a series of parametric studies are presented. Overall, the proposed bond-slip model and explicit derivations provide complete understanding of bonded FRP on concrete, as opposed to the partial understanding provided by empirical and semi-empirical models available in the literature.
\end{abstract}

Keywords: Bond-slip model; Epoxy bonded external FRP; Retrofitting of concrete structures.

Preprint submitted to Journal of $E^{A} T_{E} X$ Templates

June 2, 2020 


\section{Introduction}

Retrofitting of reinforced concrete (RC) structures, which show signs of distress or are deficient in load carrying capacity, is the most economical and sustainable option compared to rebuilding. Hence, researchers around the world

5 have been developing various retrofitting techniques, one of them being the use of epoxy-bonded external reinforcements on the concrete surface. In the last two decades, fibre reinforced polymer (FRP) materials like carbon, aramid, glass and basalt fibres have been used, due to their good immunity to corrosion, lower selfweight and excellent mechanical properties, whilst allowing hand lay-up of FRP

10

To attain a suitable strengthening system for concrete structures, adequate stress distribution between externally bonded fibre reinforced polymer (FRP) materials and the concrete substrate must be developed [4. Indeed, a number of failure modes in FRP-strengthened RC members are directly caused by nomic design of externally bonded FRP systems needs a sound understanding of the behaviour of FRP-to-concrete interfaces. In order to understand the behaviour of the epoxy bonded reinforcement to the concrete substrate, various approaches have been developed: firstly, empirical bond-strength models of the system were derived using the curve-fitting approach with basic material and geometric properties; secondly, bond-slip models with fracture toughness [8, 9, 10, where energy required to propagate a crack along the FRP was considered and the maximum load resistance and effective length equations were developed using fracture toughness; thirdly, analytical derivation of bond-slip models based on equilibrium conditions was developed by Wu et al [11. The samples exhibited mixed mode debonding failure (especially for the double cantilever beam test setup [12]), the mixed phenomenon were separated into mode I bond-separation model and mode II bond-slip model. To predict the overall be-

haviour of bonded reinforcement, both modes were superimposed and analytical 

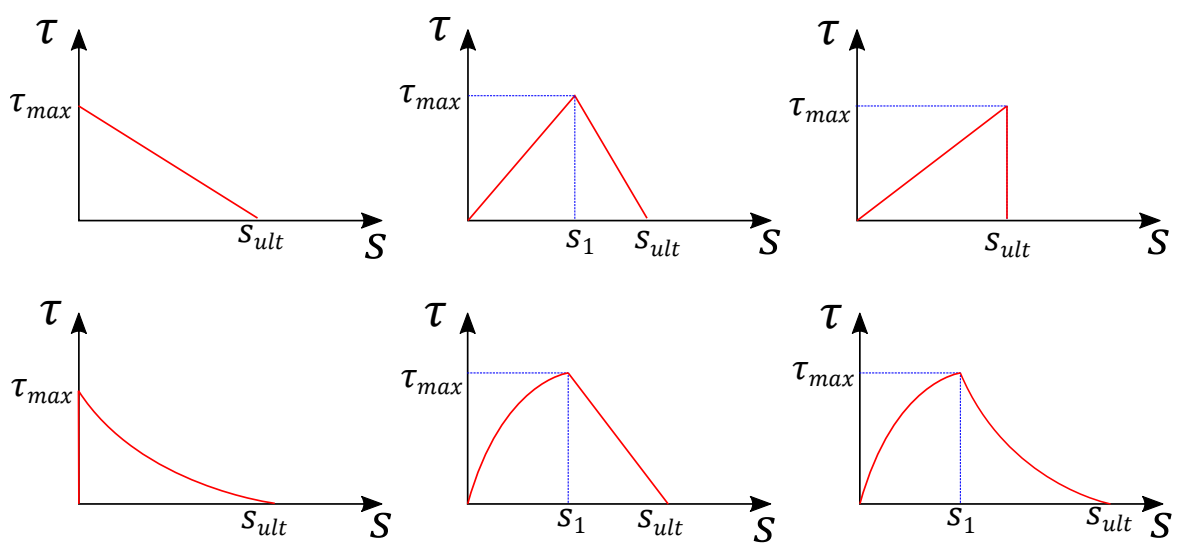

Figure 1: Various bond-slip models available in the literature

derivations were developed [13, 14].

Each approach has its own merits and drawbacks. Empirical bond-strength models provide a set of formulae to obtain the maximum bond resistance and effective bond length, which are often desired in the design environment. However, this approach does not provide stress or strain distributions along the FRP. Therefore, validation of such models were purely based on the load resistance recorded during single or double lap shear tests in the literature. Furthermore, these empirical formulae must be modified when non-standard materials are used (concrete, FRP or epoxy glue), as the existing bond-strength models were calibrated for a specific set of experimental parameters.

In the case of semi-empirical bond-slip models with fracture toughness, various simplifications and assumptions were implemented to obtain implicit formulae for the maximum force resistance, effective bond length, stress-strain distributions along the FRP. In addition, those characteristics are dictated by the type of bond-slip model considered in the first place. In the literature, various bond stress $(\tau)$ vs. slip $(s)$ relationships between the FRP and concrete were considered, as illustrated in Figure 1. This approach is too limiting for a specific configuration and materials.

Wu et al [11] reported a closed form solution based on a bond-slip model, which was developed by Dai et al [15] and Zhou et al [16. Wu et al's [11] theoret- 
ical derivation allows examination of all the essential outputs and understanding of the behaviour of the bond between FRP and concrete. However, the single curve bond-slip model used for the derivation is not explicitly stated, together with the characteristics of the bond properties and values of the constants.

It should be noted that the types of concrete, reinforcement and epoxy used in the construction industry are fast changing [17, 18, 19, 20] and layup techniques and workmanship influences the effectiveness of the bond-slip characteristics $21,22,23$. In addition, recent studies show that the bond properties vary with repeated loading [24, 25, 26] and temperature of the system [27, 28, 29. or entirely different bond-slip model altogether must be considered for any new configuration, non-standard materials and environment. Reliance on the empirical and semi-empirical models requires a substantial amount of experimental investigation and is therefore not viable.

In order to understand the behaviour of the interface between reinforcement and concrete, a combination of non-linear and linear bond-slip relationships, which can be transformed in to a few different bond-slip models by changing the bond properties, were considered. Explicit stress and strain distributions along the FRP, effective bond length, maximum load capacity and load-slip relation70 ship were mathematically derived from first principles (equilibrium conditions). This paper provides the complete mathematical derivations and validation using existing experimental results in the literature. Thus the efficient and robust analytical derivation for the bond-slip model can be used in any configuration (single or double lap shear tests), type of concrete (lightweight, recycled or high 75 strength concrete), reinforcement (carbon, aramid, glass or basalt FRPs) and epoxy glues. 

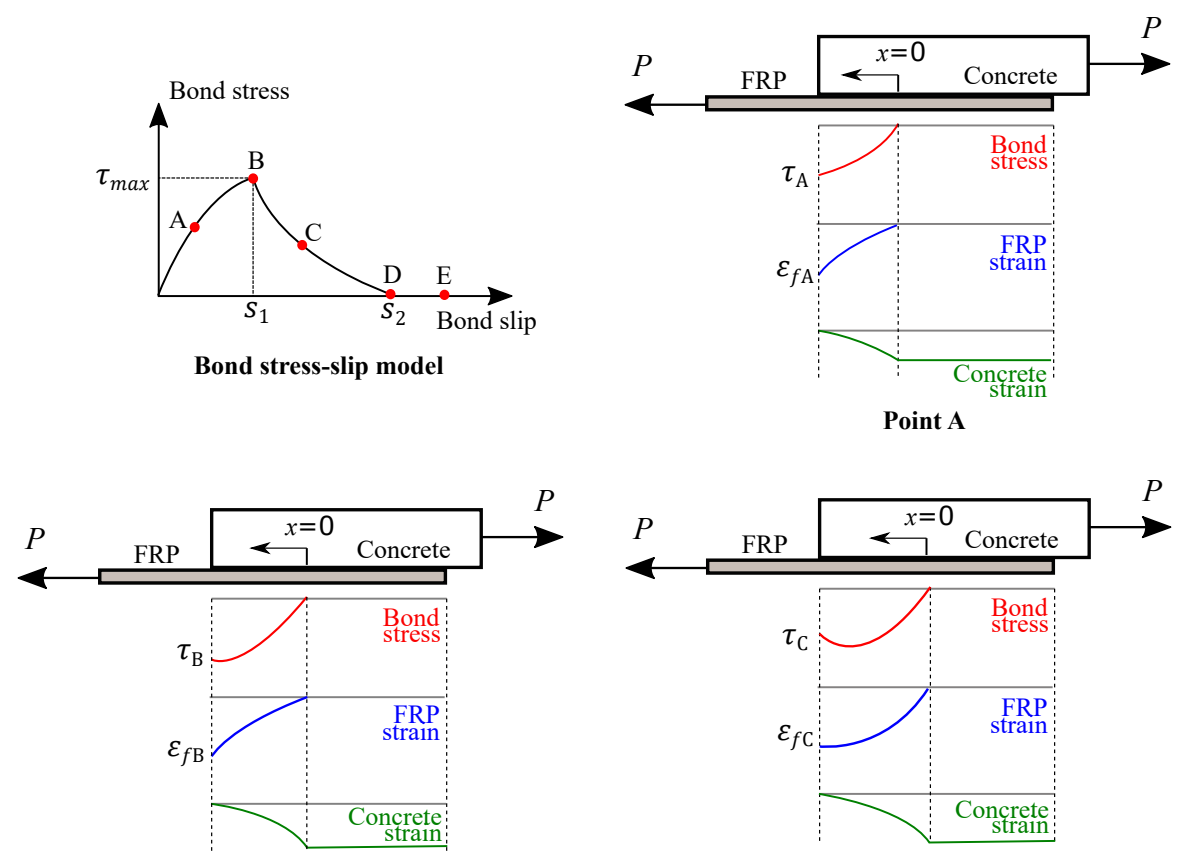

Point B

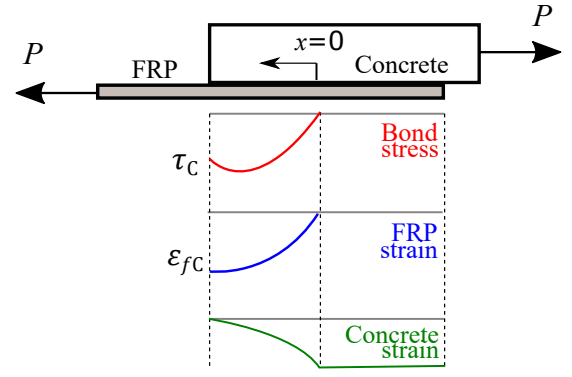

Point C

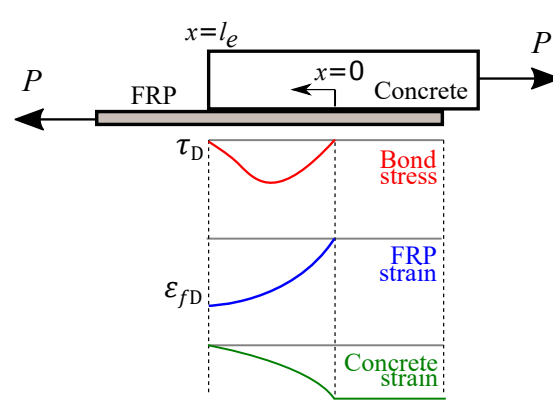

Point D

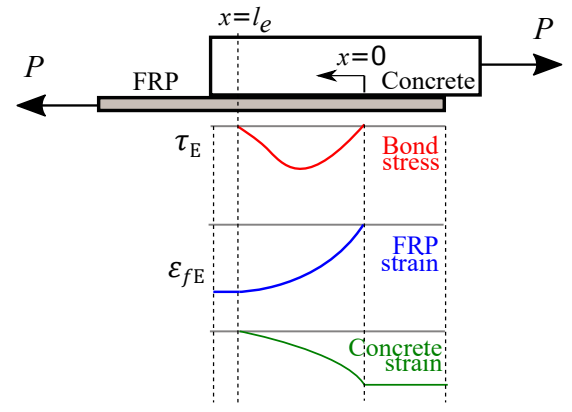

Point E

Figure 2: Stages of bond stress and strains of a bond-slip model 


\section{Theoretical derivation of a governing equation for the bond stress- slip model}

\subsection{Distributions of stresses and strains}

80 are distributed to the fibre reinforced polymer (FRP) laminates. The process of force transfer from the concrete to the FRP laminate, through bond, is described in Figure 2. The bond stress between the FRP laminate and the concrete is given by $\tau$ and the strain is denoted by $\epsilon$. Up to point A, the bond forces the force in the laminate is a maximum. In this range the strain distribution in the FRP versus slip along the length to the point of the initiation of the bond $(x=0)$ is of quadratic form. With continued loading, points $\mathrm{B}$ and $\mathrm{C}$ are reached on the bond stress versus slip curve, and the micro-cracks start formation of the macro-crack, the load carrying capacity of the joint does not increase and the length of bond through which the inter-facial shear stresses are transferred to the substrate can be defined as the effective bond length $l_{e}$ as shown in points $\mathrm{D}$ on the bond stress versus slip curve. Along the bonded region, curve, any attempt to increase the applied load beyond this point leads to a rapid shifting of the unbonded region to the free edge, causing brittle instantaneous failure as the FRP peels off completely from the surface of the concrete. Failure occurs suddenly as the energy stored in the specimen is released and the test becomes unstable 30 .

\subsection{Derivation of a governing equation}

The slip between FRP sheet and the concrete substrate at any point $x$ along the bonded length of FRP sheet is the difference between the longitudinal displacement of the FRP and that of the concrete [31, 11, 32.

$$
s=u_{f}-u_{c}
$$



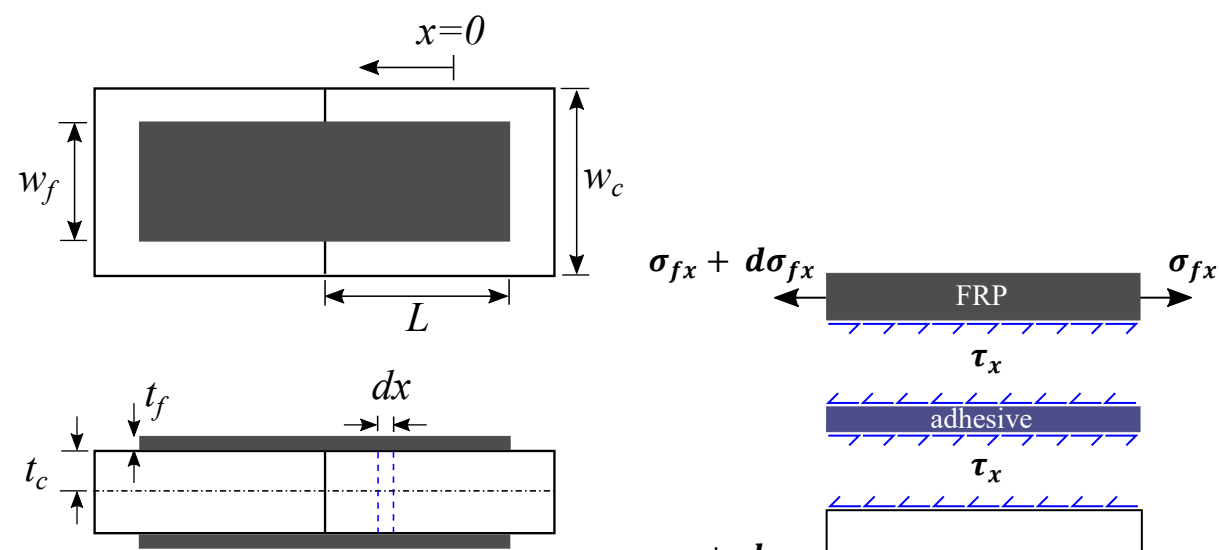

(a)
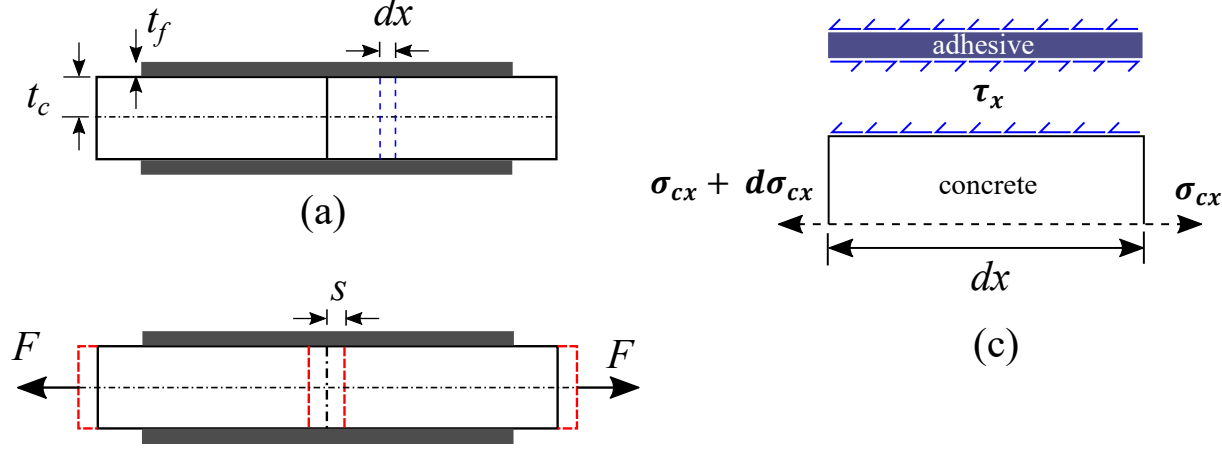

(c)

(b)

Figure 3: Detail of FRP-concrete joint (a) two separate concrete blocks bonded together with FRP sheet (b) relative displacement between concrete and FRP reinforcement(c)differential segment of the adhesively bonded joint

where, $s$ is the bond slip; $u_{f}$ and $u_{c}$ are the FRP and concrete displacement respectively. For the derivation of this governing equation, the double lap shear test specimen was considered as shown in Figure 3. According to Figure 3 (b), the slip is expressed as the relative displacement between the FRP and concrete.

Figure 3 (c) shows the equilibrium of the applied stresses and compatibility of deformations in a finite element of the joint. It must be noted that the origin of $x$ moves towards the restrained end as the force is applied as illustrated in Figures 2 and 3.

In elastic models, the strain-stress relationship for interface materials can be expressed in the following linear formulation. The axial stress in concrete $\left(\sigma_{c}\right)$ 
and FRP reinforcement $\left(\sigma_{f}\right)$ can be written as:

$$
\sigma_{c}=E_{c} \epsilon_{c} \quad \text { and } \quad \sigma_{f}=E_{f} \epsilon_{f}
$$

where, $E_{c}$ and $E_{f}$ are the elastic modulus of concrete and FRP reinforcement, respectively. The concrete strain $\left(\epsilon_{c}\right)$ and $\operatorname{FRP}$ strain $\left(\epsilon_{f}\right)$ are defined by the following equations:

$$
\epsilon_{c}=\frac{\mathrm{d} u_{c}}{\mathrm{~d} x} \quad \text { and } \quad \epsilon_{f}=\frac{\mathrm{d} u_{f}}{\mathrm{~d} x}
$$

By differentiating Equation 1

$$
\frac{\mathrm{d} s}{\mathrm{~d} x}=\frac{\mathrm{d} u_{f}}{\mathrm{~d} x}-\frac{\mathrm{d} u_{c}}{\mathrm{~d} x}=\epsilon_{f}-\epsilon_{c}=\frac{\sigma_{f}}{E_{f}}-\frac{\sigma_{c}}{E_{c}}
$$

Differentiating Equation 4 yields:

$$
\frac{\mathrm{d}^{2} s}{\mathrm{~d} x^{2}}=\frac{\mathrm{d} \epsilon_{f}}{\mathrm{~d} x}-\frac{\mathrm{d} \epsilon_{c}}{\mathrm{~d} x}=\frac{1}{E_{f}} \frac{\mathrm{d} \sigma_{f}}{\mathrm{~d} x}-\frac{1}{E_{c}} \frac{\mathrm{d} \sigma_{c}}{\mathrm{~d} x}
$$

A differential section $d_{x}$ can be cut from the FRP-to-concrete bonded sample as shown in Figure 3(c). This is constructed from three materials: concrete, adhesive layer and FRP reinforcement. In the present analysis, linear elastic behaviour is assumed for all the materials; the adhesive is assumed to only play a role in transferring the stresses from the concrete to the FRP reinforcement and the direct stress orthogonal to the plane of the adhesive layer does not change through the thickness. The interfacial shear and the axial stresses in the FRP reinforcement are denoted by $\tau$ and $\sigma_{f}$ respectively. The equilibrium force in FRP reinforcement in the $\mathrm{x}$-direction gives:

$$
\tau d_{x} b_{f}=d \sigma_{f} b_{f} t_{f} \Rightarrow \tau=t_{f} \frac{\mathrm{d} \sigma_{f}}{\mathrm{~d} x}
$$

The equilibrium in the FRP-concrete joint in the $\mathrm{x}$-direction gives:

$$
d \sigma_{f} b_{f} t_{f}+d \sigma_{c} b_{c} t_{c}=0 \Rightarrow d \sigma_{c}=-\frac{d \sigma_{f} t_{f} b_{f}}{t_{c} b_{c}}
$$

By substituting Equation 7 into Equation 5 gives:

$$
\frac{\mathrm{d}^{2} s}{\mathrm{~d} x^{2}}=\frac{\mathrm{d} \sigma_{f}}{\mathrm{~d} x} \frac{E_{c} t_{c} b_{c}+E_{f} t_{f} b_{f}}{E_{f} E_{c} t_{c} b_{c}}
$$


Substituting $\frac{\mathrm{d} \sigma_{f}}{\mathrm{~d} x}$ from Equation 6 gives:

$$
\frac{\mathrm{d}^{2} s}{\mathrm{~d} x^{2}}=\tau \frac{E_{c} t_{c} b_{c}+E_{f} t_{f} b_{f}}{E_{f} t_{f} E_{c} t_{c} b_{c}}=K \tau
$$

where,

$$
K=\frac{E_{c} t_{c} b_{c}+E_{f} t_{f} b_{f}}{E_{f} t_{f} E_{c} t_{c} b_{c}}
$$

\section{Single lap shear test}

In the case of a single lap shear test, the concrete block is often rigidly fixed to the strong floor or the test rig using using steel anchorage. Stiffness of the steel anchorage is significantly higher than the bonded FRP system. Therefore, concrete substrate is fully confined and no changes in dimensions are expected in the concrete substrate. Therefore, elongation in the force direction is negligible. Hence, Equation 1 can be written as:

$$
s=u_{f}
$$

The second order derivation (Equation 5 can be given as:

$$
\frac{\mathrm{d}^{2} s}{\mathrm{~d} x^{2}}=\frac{1}{E_{f}} \frac{\mathrm{d} \sigma_{f}}{\mathrm{~d} x}
$$

By replacing the derivative component using Equation 6 .

$$
\frac{\mathrm{d}^{2} s}{\mathrm{~d} x^{2}}=\frac{\tau}{E_{f} t_{f}}=K \tau
$$

Hence, the value of $K$ can be given as:

$$
K=\frac{1}{E_{f} t_{f}}
$$




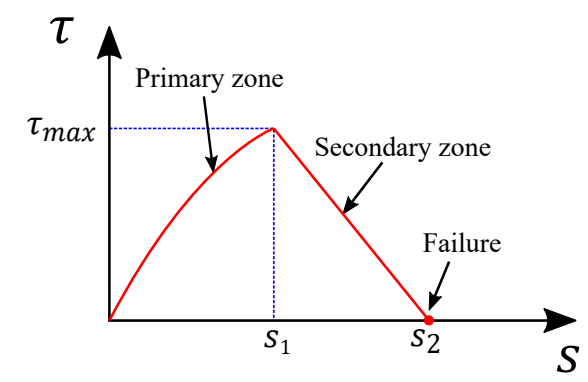

Figure 4: Proposed bond-slip model

\section{Bond stress-slip model and theoretical derivations}

For this derivation, non-linear ascending (primary) and linear descending (secondary) branches of a bond-slip model were considered (Figure 4):

$$
\tau= \begin{cases}\tau_{\max }\left(\frac{s}{s_{1}}\right)^{\alpha} & 0 \leq s \leq s_{1} \\ \tau_{\max }\left(\frac{s_{2}-s}{s_{2}-s_{1}}\right) & s_{1} \leq s \leq s_{2} \\ 0 & s_{2} \leq s\end{cases}
$$

where $s_{1}$ and $s_{2}$ are the values of slip which demonstrate each region of behaviour, $\tau_{\max }$ is the maximum bond stress, and $\alpha$ is a constant that defines the non-linear ascending and descending curve of the bond stress-slip model (Figure 4). This model allows to reduce to a bi-linear model by assuming $\alpha$ is unity.

The debonding process of the externally bonded FRP reinforcement from the concrete substrate can be summarised in three main stages: increase in bond stress up to maximum bond stress $\left(\tau_{\max }\right)$ and corresponding slip $\left(s_{1}\right)$ (here after known as the primary zone), the softening or decrease of bond stress until zero bond stress and corresponding slip $\left(s_{2}\right)$ (here after known as the secondary zone), and local debonding after reaching the ultimate slip (failure stage).

Before reaching the maximum bond stress, the area within the primary zone is uncracked. After the maximum bond stress is achieved, interfacial softening due to micro-cracking occurs in the area within the secondary zone. The maximum axial load is reached when sufficient bond length of the FRP reinforcement 
135 known as the effective length, $l_{e}$. After this instance, the debonding commences beyond the failure point while slip increases without any drop in load resistance.

If sufficient bond length of FRP reinforcement is available, the maximum shear stress will be reached closer to the free end of the FRP as the slip increases

When the slip between FRP and concrete occurs $\left(s \leq s_{1}\right)$, the primary zone is activated as shown in Figure 5 (b). The bond stress in the primary zone is defined by the following equation:

$$
\tau_{p}=\tau_{\max }\left(\frac{s}{s_{1}}\right)^{\alpha}
$$

The equation can be simplified to:

$$
\tau_{p}=\rho_{1} s^{\alpha}
$$

where, $\rho_{1}=\frac{\tau_{\max }}{s_{1}^{\alpha}}$. Substitution of Equation 17 into Equation 9 gives:

$$
\frac{\mathrm{d}^{2} s}{\mathrm{~d} x^{2}}=K \rho_{1} s^{\alpha}
$$

where $K$ is the constant for an experimental set-up, $\rho_{1}$ is constant for the proposed bond-slip model and $\alpha$ has a positive value (according to most of the existing bond-slip models, $0 \leq \alpha \leq 1$ ). Solution of this non-linear second order differential equation 18 can be obtained from the Emden-Fowler solution [33. The solution can be given as:

$$
x= \pm \int\left(\frac{2 K \rho_{1}}{\alpha+1} s^{\alpha+1}+C_{1}\right)^{-\frac{1}{2}} d s+C_{2}
$$


(a)
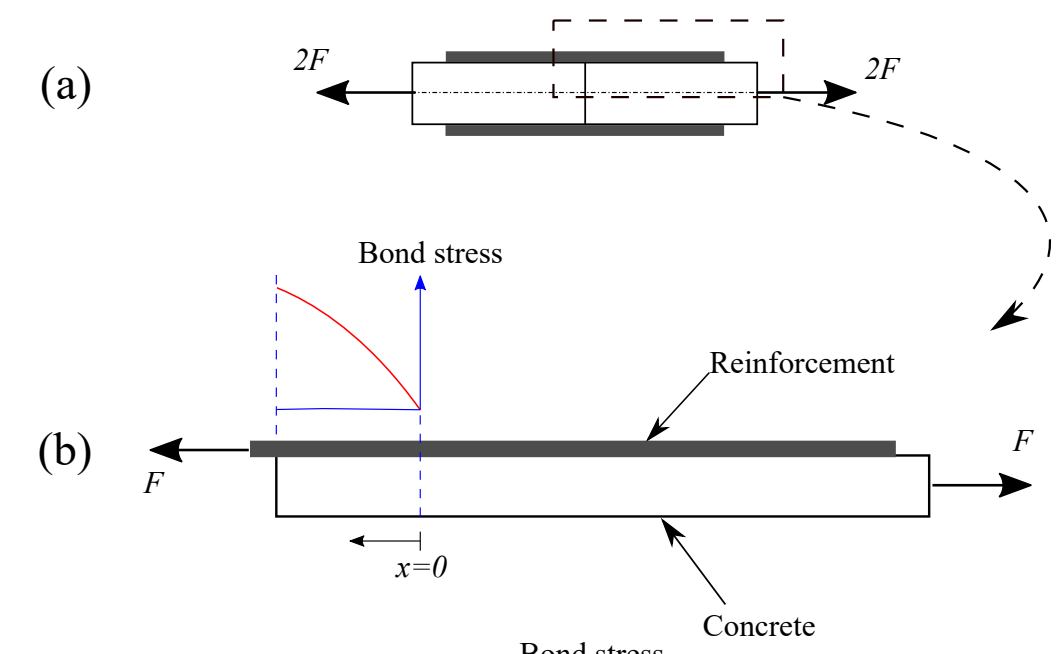

(c)

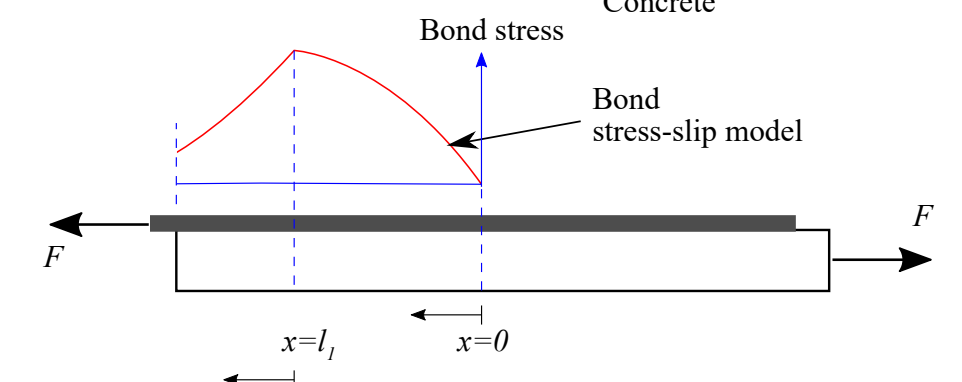

$$
\longleftarrow x x=0
$$

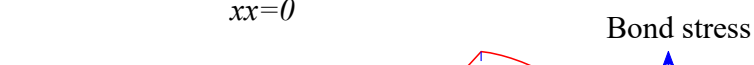

(d)

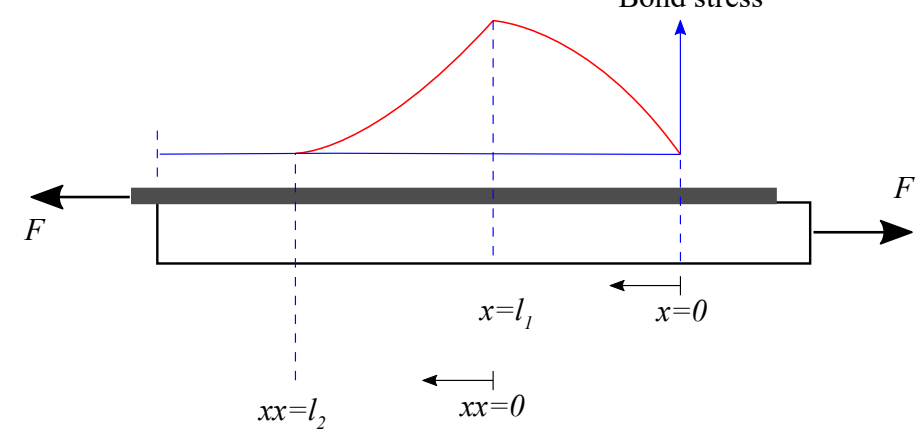

Figure 5: (a) Double-lap bond shear-slip test; (b) primary zone; (c) primary and secondary zones; (d) primary, secondary and failed zones 
where, $C_{1}$ and $C_{2}$ are constants. Derivation with respect to $s$ on both sides of the equation will give:

$$
\frac{\mathrm{d} x}{\mathrm{~d} s}= \pm\left(\frac{2 K \rho_{1}}{\alpha+1} s^{\alpha+1}+C_{1}\right)^{-\frac{1}{2}}
$$

According to the generalised bond stress-slip model, slip $(s)$ is 0 at $x=0$. Furthermore, all the bond stress-slip models available in the literature suggest the slip gradient with respect to distance $\left(\frac{\mathrm{d} s}{\mathrm{~d} x}\right)$ is 0 at $x=0$ [11]. Therefore, the constants $C_{1}$ and $C_{2}$ become 0 for these boundary conditions. Hence, equation 19 can be rearranged as:

$$
s=\left(\frac{K \rho_{1}(1-\alpha)^{2}}{2(1+\alpha)}\right)^{\frac{1}{1-\alpha}} x^{\frac{2}{1-\alpha}}
$$

So the first order differentiation (Equation 20) can be written as:

$$
\frac{\mathrm{d} s}{\mathrm{~d} x}=\left(\frac{2 K \rho_{1}}{1+\alpha}\right)^{\frac{1}{2}} s^{\frac{1+\alpha}{2}}
$$

Based on the solution, the distance along the FRP in the primary zone from Equation 21 can be rearranged as:

$$
x=\left(\frac{2(1+\alpha)}{K \rho_{1}(1-\alpha)^{2}}\right)^{\frac{1}{2}} s^{\frac{1-\alpha}{2}}
$$

The bond stress along the FRP reinforcement at distance $x$ can be derived by substituting Equation 21 into Equation 17 as:

$$
\tau_{p}=\rho_{1}\left(\frac{K \rho_{1}(1-\alpha)^{2}}{2(1+\alpha)}\right)^{\frac{\alpha}{1-\alpha}} x^{\frac{2 \alpha}{1-\alpha}}
$$

By integrating Equation 24, the force associated with the primary zone from the origin of $x$ can be obtained as:

$$
F_{p}=b_{f} \int_{0}^{x} \tau_{p} d x=b_{f} \rho_{1}\left(\frac{K \rho_{1}(1-\alpha)^{2}}{2(1+\alpha)}\right)^{\frac{\alpha}{1-\alpha}} \frac{x^{\frac{1+\alpha}{1-\alpha}}}{\frac{1+\alpha}{1-\alpha}}
$$

The maximum force from the primary zone can be given as:

$$
F_{p, \text { max }}=b_{f} \int_{0}^{l_{1}} \tau_{p} d x=b_{f} \rho_{1}\left(\frac{K \rho_{1}(1-\alpha)^{2}}{2(1+\alpha)}\right)^{\frac{\alpha}{1-\alpha}} \frac{l_{1}^{\frac{1+\alpha}{1-\alpha}}}{\frac{1+\alpha}{1-\alpha}}
$$


where $l_{1}$ is the length along the reinforcement from $x=0$ to the where the slip is $s_{1}$. The FRP strain distribution along the length in the primary zone can be given as:

$$
\epsilon_{f}=\frac{1}{E_{f} t_{f}} \int_{0}^{x} \tau_{p} d x=\frac{F_{p}}{t_{f} b_{f} E_{f}}
$$

Based on the bond-slip model considered for this derivation, bond stress and strain distributions along the reinforcement and load-slip curve can be obtained if the parameters $s_{1}$ and $\alpha$ are known for either double or single shear tests.

\subsection{Primary and secondary zones}

The secondary zone is activated when the slip between the FRP and concrete exceeds $s_{1}$, as shown in Figure 5 (c). The primary zone remains and moves along the sample length. The maximum primary zone length from Equation 23 can be written as:

$$
l_{1}=\left(\frac{2(1+\alpha)}{K \rho_{1}(1-\alpha)^{2}}\right)^{\frac{1}{2}} s_{1}^{\frac{1-\alpha}{2}}
$$

At the boundary between the primary zone and the secondary zone, the first order differentiation from Equation 20 can be given as:

$$
\left(\frac{\mathrm{d} s}{\mathrm{~d} x}\right)_{l_{1}}=\left(\frac{2 K \rho_{1}}{1+\alpha}\right)^{\frac{1}{2}} s_{1}^{\frac{1+\alpha}{2}}
$$

The bond stress-slip model for the secondary zone can be given by (Equation 15):

$$
\tau_{s}=\tau_{\max } \frac{s_{2}-s}{s_{2}-s_{1}}
$$

By substituting Equation 30 into Equation 9 gives:

$$
\frac{\mathrm{d}^{2} s}{\mathrm{~d} x^{2}}=K\left(\rho_{2}-\rho_{3} s\right)
$$

where, $\rho_{2}=\frac{\tau_{\max } s_{2}}{s_{2}-s_{1}}$ and $\rho_{3}=\frac{\tau_{\max }}{s_{2}-s_{1}}$. Equation 31 is a second-order non-linear non-homogeneous differential equation. Solution of this equation can be given as:

$$
s=B_{1} \sin \left(x x \sqrt{K \rho_{3}}\right)+B_{2} \cos \left(x x \sqrt{K \rho_{3}}\right)+\frac{\rho_{2}}{\rho_{3}}
$$

where, $B_{1}$ and $B_{2}$ are constants. It should be noted that the local distance along the FRP for the secondary zone is denoted by $x x$ compared to global distance 
$x$. Therefore, $x=l_{1}$ for $x x=0$ (Figure $5(\mathrm{c})$ ). Differentiation of Equation 32 can be written as:

$$
\frac{\mathrm{d} s}{\mathrm{~d} x x}=\sqrt{K \rho_{3}}\left(B_{1} \cos \left(x x \sqrt{K \rho_{3}}\right)-B_{2} \sin \left(x x \sqrt{K \rho_{3}}\right)\right)
$$

Equations 32 and 33 for the secondary zone are required to comply with the equilibrium and compatibility conditions. Hence, $s$ and $\frac{\mathrm{d} s}{\mathrm{~d} x}$ (Equations 28 and 29 at the end of the primary zone can be used as boundary conditions on Equations 32 and 33 , which leads to:

$$
B_{1}=\left(\frac{2 \rho_{1}}{\rho_{3}(1+\alpha)}\right)^{\frac{1}{2}} s_{1}^{\frac{1+\alpha}{2}}
$$

and,

$$
B_{2}=s_{1}-s_{2}
$$

Constants $B_{1}$ and $B_{2}$ depend on the characteristic of the proposed bond-slip model. Therefore, the relationship between the maximum distance along the bond length for the secondary zone $l_{2}$ and corresponding slip $s_{2}$ can be given as:

$$
s_{2}=B_{1} \sin \left(l_{2} \sqrt{K \rho_{3}}\right)+B_{2} \cos \left(l_{2} \sqrt{K \rho_{3}}\right)+\frac{\rho_{2}}{\rho_{3}}
$$

The maximum length for the secondary zone bond length $l_{2}$ can be given as:

$$
l_{2}=\frac{1}{\sqrt{K \rho_{3}}} \tan ^{-1}\left(\frac{-B_{2}}{B_{1}}\right)
$$

Hence, the effective length can be given as:

$$
l_{e}=l_{1}+l_{2}=\left(\frac{2(1+\alpha)}{K \rho_{1}(1-\alpha)^{2}}\right)^{\frac{1}{2}} s_{1}^{\frac{1-\alpha}{2}}+\frac{1}{\sqrt{K \rho_{3}}} \tan ^{-1}\left(\frac{-B_{2}}{B_{1}}\right)
$$

The secondary zone force can be obtained using the following equation:

$$
F_{s}=b_{f} \int_{0}^{x x} \tau_{s} d x x=b_{f} \int_{0}^{x x}\left(\rho_{2}-\rho_{3} s\right) d x x
$$

By substituting Equation 32 and solving the integration, the force corresponding to the secondary zone can be given as:

$$
F_{s}=b_{f} \sqrt{\frac{\rho_{3}}{K}}\left(B_{1} \cos \left(x x \sqrt{K \rho_{3}}\right)-B_{1}-B_{2} \sin \left(x x \sqrt{K \rho_{3}}\right)\right)
$$


For the fully developed secondary zone $\left(x x=l_{2}\right)$, the maximum force can be given as:

$$
F_{s, \max }=b_{f} \sqrt{\frac{\rho_{3}}{K}}\left(B_{1} \cos \left(l_{2} \sqrt{K \rho_{3}}\right)-B_{1}-B_{2} \sin \left(l_{2} \sqrt{K \rho_{3}}\right)\right)
$$

The maximum debonding load can be obtained by adding Equations 26 and 41

$$
F_{\max }=F_{p, \max }+F_{s, \max }
$$

The FRP strain in the secondary zone can be obtained as:

$$
\epsilon_{f}=\frac{1}{E_{f} t_{f}} \int_{0}^{l_{1}} \tau_{p} d x+\frac{1}{E_{f} t_{f}} \int_{l_{1}}^{x} \tau_{s} d x=\frac{F_{p, \max }}{t_{f} b_{f} E_{f}}+\frac{F_{s}}{t_{f} b_{f} E_{f}}
$$

Hence, the maximum FRP strain can be obtained as:

$$
\epsilon_{f, \max }=\frac{F_{p, \max }}{t_{f} b_{f} E_{f}}+\frac{F_{s, \max }}{t_{f} b_{f} E_{f}}=\frac{F_{\max }}{t_{f} b_{f} E_{f}}
$$

\subsection{Transform-ability of the model and its derivations}

Most of the bond-slip models proposed in the literature are either linear and/or bi-linear. Various combination of bond-slip parameters were proposed based on linear or bi-linear models. Hence, adaptability of any newly proposed model and derivations would enhance the usability. This proposed model can be transformed in to linear or bi-linear models by varying the bond-slip parameters, which increase the usage of this bond-slip model and its derivations. Figure 6 shows the linear and bi-linear bond-slip models and bond parameters that correspond to those models. By applying those bond parameters in equations 42 and 38 , the maximum load resistance and effective bond length can be reduced to simpler forms.

\section{Estimation of bond-slip model parameters}

\subsection{Existing experimental results in the literature}

Experimental test results were collated to create datasets by Chen and Teng [7; Lu et al [10; Wu et al [34; Bilotta et al [35, 36]; Wu and Jiang [32]; 


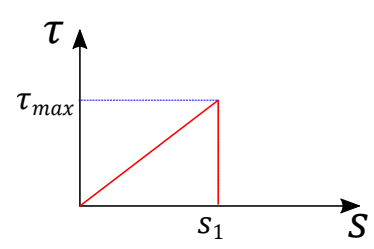

(a)

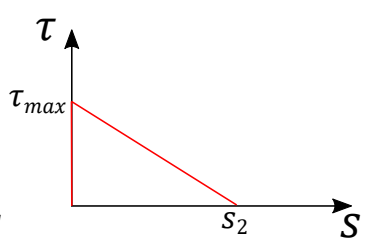

(b)

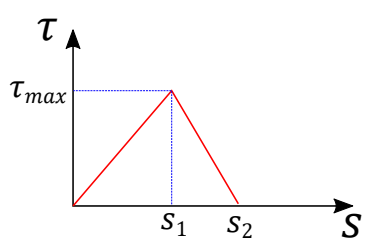

(c)

Figure 6: (a) Linear primary zone alone $\left(\alpha=1 ; s_{1}=s_{2}\right)$ (b) linear secondary zone alone $\left(\alpha=N / A ; s_{1}=0\right)(\mathrm{c})$ linear primary and secondary zones $(\alpha=1)$

Serbescu et al [37, which were used for the validation of their empirical, semiempirical and theoretical models. The theoretical model reported in this paper was derived from first principles (equilibrium conditions). Furthermore, this theoretical model introduces a different geometric constant $K$ (see Equations 10, 14 to single or double lap shear tests, based on confined or unconfined test 42, 43, 44, 45, 46, 47] are considered for this study. Furthermore, the number of data points were increased using experiential results reported recently by Al-Allaf et al [48, 17, where only samples failed due to de-bonding of FRP or adhesive failure were considered for this study.

\subsection{Bond-slip models used for the estimation the parameters}

As described, the parameters of a bond-slip model vary depending on the type of model (linear or non-linear; single or double curve(s)). To obtain the bond parameters for the proposed models $\left(\tau_{\max }, \alpha, s_{1}\right.$ and $\left.s_{2}\right)$, various bond-slip models available in the literature and corresponding parameters were considered, as shown in Table 1

In the literature, the bond-slip parameters were obtained by curve-fitting the experimental results. Nakaba et al [8] proposed a single mathematical equation (single curve) for the bond stress-slip model. Savioa et al [50] further refined Nakaba et al's model by changing the empirical constants. Parameters for these models are purely dependent on the material properties of concrete and empirical constants, while the rest of the bond-slip models' parameters are dependent 
Table 1: Models used for the estimation of bond-slip model parameters

\begin{tabular}{|c|c|c|c|}
\hline Bond-slip model & $\begin{array}{l}\text { Ascending } \\
\text { (primary) }\end{array}$ & $\begin{array}{l}\text { Descending } \\
\text { (secondary) }\end{array}$ & $\begin{array}{l}\text { Bond-slip } \\
\text { parameters }\end{array}$ \\
\hline $\begin{array}{l}\text { Neubauer and } \\
\text { Rostasy } 49\end{array}$ & $\tau_{\max } \frac{s}{s_{1}}$ & 0 & $\begin{array}{l}\tau_{\max }=1.8 \beta_{w} f_{t} \\
\alpha=1^{\dagger} \\
s_{1}=0.202 \beta_{w} \\
s_{2}=s_{1} \\
\beta_{w}=\sqrt{\frac{1.125\left(2-b_{f} / b_{c}\right)}{1+b_{f} / 400}}\end{array}$ \\
\hline Monti et al 9 & $\tau_{\max } \frac{s}{s_{1}}$ & $\tau_{\max } \frac{s_{2}-s}{s_{2}-s_{1}}$ & $\begin{array}{l}\tau_{\max }=1.8 \beta_{w} f_{t} \\
\alpha=1^{\dagger} \\
s_{1}=2.5 \tau_{\max }\left(\frac{t_{a}}{E_{a}}+\frac{50}{E_{c}}\right) \\
s_{2}=0.33 \beta_{w} \\
\beta_{w}=\sqrt{\frac{1.5\left(2-b_{f} / b_{c}\right)}{1+b_{f} / 100}}\end{array}$ \\
\hline $\begin{array}{l}\text { Lu et al [10] } \\
\text { Bi-linear model }\end{array}$ & $\tau_{\max } \frac{s}{s_{1}}$ & $\tau_{\max } \frac{s_{2}-s}{s_{2}-s_{1}}$ & $\begin{array}{l}\tau_{\max }=1.5 \beta_{w} f_{t} \\
\alpha=1^{\dagger} \\
s_{1}=0.0195 \beta_{w} f_{t} \\
s_{2}=\frac{0.616 \beta_{w}^{2} \sqrt{f_{t}}}{\tau_{\max }} \\
\beta_{w}=\sqrt{\frac{2-b_{f} / b_{c}}{1+b_{f} / b_{c}}}\end{array}$ \\
\hline Nakaba et al 8 & $\tau_{\max } \frac{s}{s_{1}}$ & $\left.3 /\left(2+\left(s / s_{1}\right)^{3}\right)\right)^{+}$ & $\begin{array}{l}\tau_{\max }=3.5 f_{c}^{0.19} \\
\alpha=0.55^{*} \\
s_{1}=0.065 \\
s_{2}=0.305^{*}\end{array}$ \\
\hline Savioa et al [50] & $\tau_{\max } \frac{s}{s_{1}}(2.8$ & $\left./\left(1.86+\left(s / s_{1}\right)^{2.86}\right)\right)^{+}$ & $\begin{array}{l}\tau_{\max }=3.5 f_{c}^{0.19} \\
\alpha=0.5^{*} \\
s_{1}=0.051 \\
s_{2}=0.264^{*}\end{array}$ \\
\hline
\end{tabular}

* estimated as described in Figure 7

+ single curve

$\dagger$ in numerical investigation, $\alpha$ was taken as 0.95 as a solution

is not possible when $\alpha=1$. 


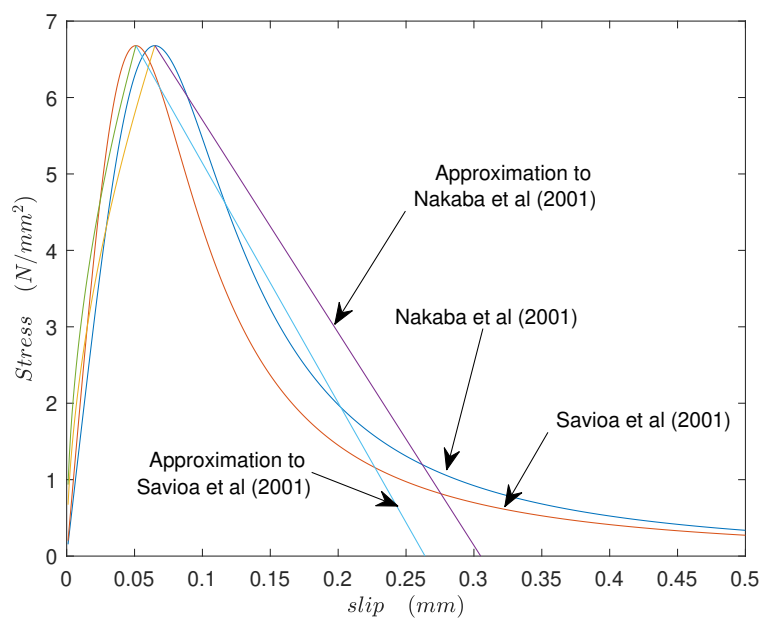

Figure 7: Nakaba et al [8] and Savioa et al's [50] approximations to proposed model using fracture energy

on the materials and geometric properties of the test specimen. For this reason, these two models are considered even though the models are not exactly the same as the proposed model. It should be noted that the empirical constants of Nakaba at al and Savioa et al's models were derived using smaller amounts of experimental data, compared to substantially larger amount of experimental data used for Lu et al's [10] model. In order to obtain the missing parameters of Nakaba et al's model $\alpha$ and $s_{2}$, fracture energy (area under the bond-slip curve) of the proposed model and Nakaba et al's model were equated, as shown in Figure 7. The same approach was considered for Savioa el al's model and the parameters are shown in Table 1.

Bond-slip parameters for each of the models were applied to the proposed model in this paper and compared to the experimental results from the literature. Firstly, effective length was calculated using equation 38 and compared to the FRP length of each sample. If the FRP length of the sample is more than the theoretical effective length, full bond-slip was developed and the maximum force resistance was calculated using equation 42 . When the FRP lengths 
Table 2: Geometry of test specimens (all dimensions are in $\mathrm{mm}$ )

\begin{tabular}{llllll}
\hline Specimen & $L$ & $b_{f}$ & $t_{f}$ & $b_{c}$ & $t_{c}$ \\
\hline BN-1 & 50 & 100 & 0.117 & 200 & 45 \\
BN-3 & 100 & 100 & 0.117 & 200 & 45 \\
\hline BL-1 & 50 & 100 & 0.117 & 200 & 45 \\
BL-3 & 100 & 100 & 0.117 & 200 & 45 \\
\hline
\end{tabular}

are smaller than theoretical effective bond length, primary and secondary zones were considered separately and the maximum force was calculated according to the bond-slip experienced in each samples. The results are illustrated in Figure 8. The results show that the parameters proposed by Lu et al [10] are a good fit compared to other models' parameters. Thus, Lu et al's parameters are used for the load-slip curve validation using results obtained by Al-Allaf et al [17, 20].

\section{Validation}

\subsection{Characteristics of the load-slip curve}

The complete load-slip curve consists of a number of points corresponding to the loading stages (Figure 10). The cracking stage starts at Point A, where the full primary zone is realized. The load continues to raise due to the presence 220 capacity at point $\mathrm{B}$, at which debonding of reinforcement is initiated. The bond length of reinforcement required to reach point $\mathrm{B}$ is known as the effective 

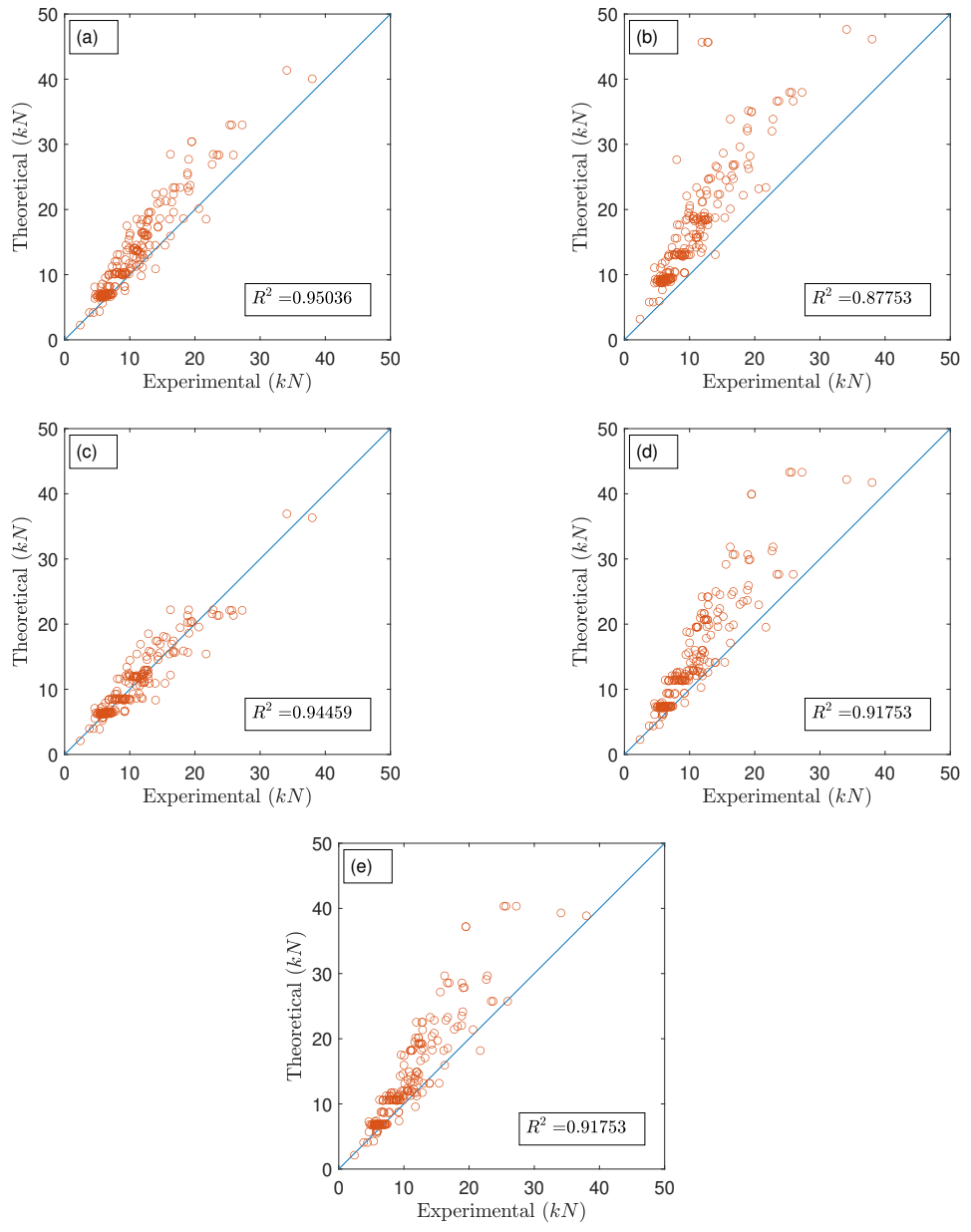

Figure 8: Comparison between experimental results and theoretical prediction using parameters suggested by (a) Neubauer and Rostasy [49]; (b) Monti et al 9]; (c) Lu et al [10]; (d) Nakaba et al [8]; (e) Savioa et al [50] 

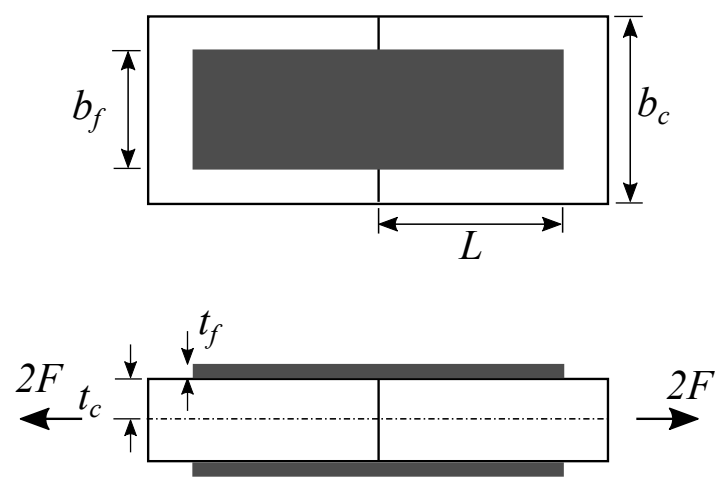

Figure 9: Double lap shear test specimen

Table 3: Mechanical properties of concrete and CFRP sheet

\begin{tabular}{lc}
\hline \multicolumn{2}{c}{ Normal concrete (BN samples) } \\
\hline Cube strength $\left(f_{c u}\right)$ & $41.6 \mathrm{~N} / \mathrm{mm}^{2}$ \\
Elastic modulus $\left(E_{c}\right)$ & $29670 \mathrm{~N} / \mathrm{mm}^{2}$ \\
\hline \multicolumn{2}{c}{ Lightweight concrete (BL samples) } \\
\hline Cube strength $\left(f_{c u}\right)$ & $40.1 \mathrm{~N} / \mathrm{mm}^{2}$ \\
Elastic modulus $\left(E_{c}\right)$ & $22900 \mathrm{~N} / \mathrm{mm}^{2}$ \\
\hline \multicolumn{2}{c}{$\mathbf{C F R P}$ sheet } \\
\hline Tensile strength $\left(f_{f}\right)$ & $4000 \mathrm{~N} / \mathrm{mm}^{2}$ \\
Elastic modulus $\left(E_{f}\right)$ & $240 \times 10^{3} \mathrm{~N} / \mathrm{mm}^{2}$ \\
\hline
\end{tabular}




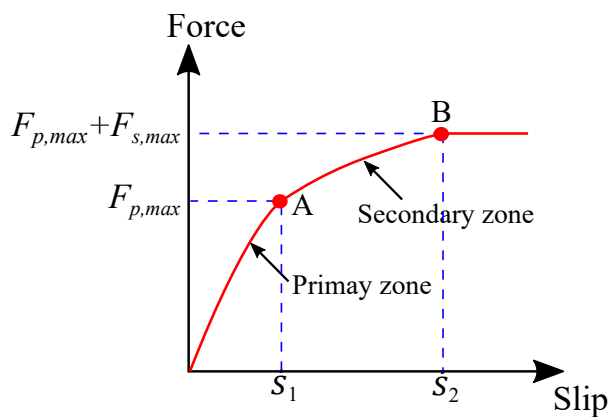

Figure 10: Characteristic load slip

length. As a result, this model provides a useful tool for the calculation of the complete load-slip behaviour of the epoxy reinforcement-concrete interface, strain distribution along the reinforcement and effective length.

\subsection{Comparison of load-slip curve}

Theoretical applied load vs. slip curves for specimens BN1-1, BN1-3, BL11 and BL1-3 (see Al-Allaf et al [17]) are calculated using the proposed model with the bond parameters proposed by Lu et al [10] and compared with the experimental results in Figure 11. The test results and the analytical results can be seen to be in good agreement. The closeness of the match with experimental results further demonstrates the excellent performance of the analytical models developed in this paper.

\section{Sensitivity studies}

\subsection{Parameters of the bond-slip model}

In order to understand the theoretical model, a series of sensitivity studies on the bond-slip parameters were carried out as shown in Figure 12. For this study, materials and geometric properties of the test results reported by Al-Allaf et al [17] were used. Whilist the effect of one parameter was being investigated, the rest of the bond-slip parameters of the proposed model were not changed as shown in Figure 12. This sensitivity study shows that the maximum bond-slip 

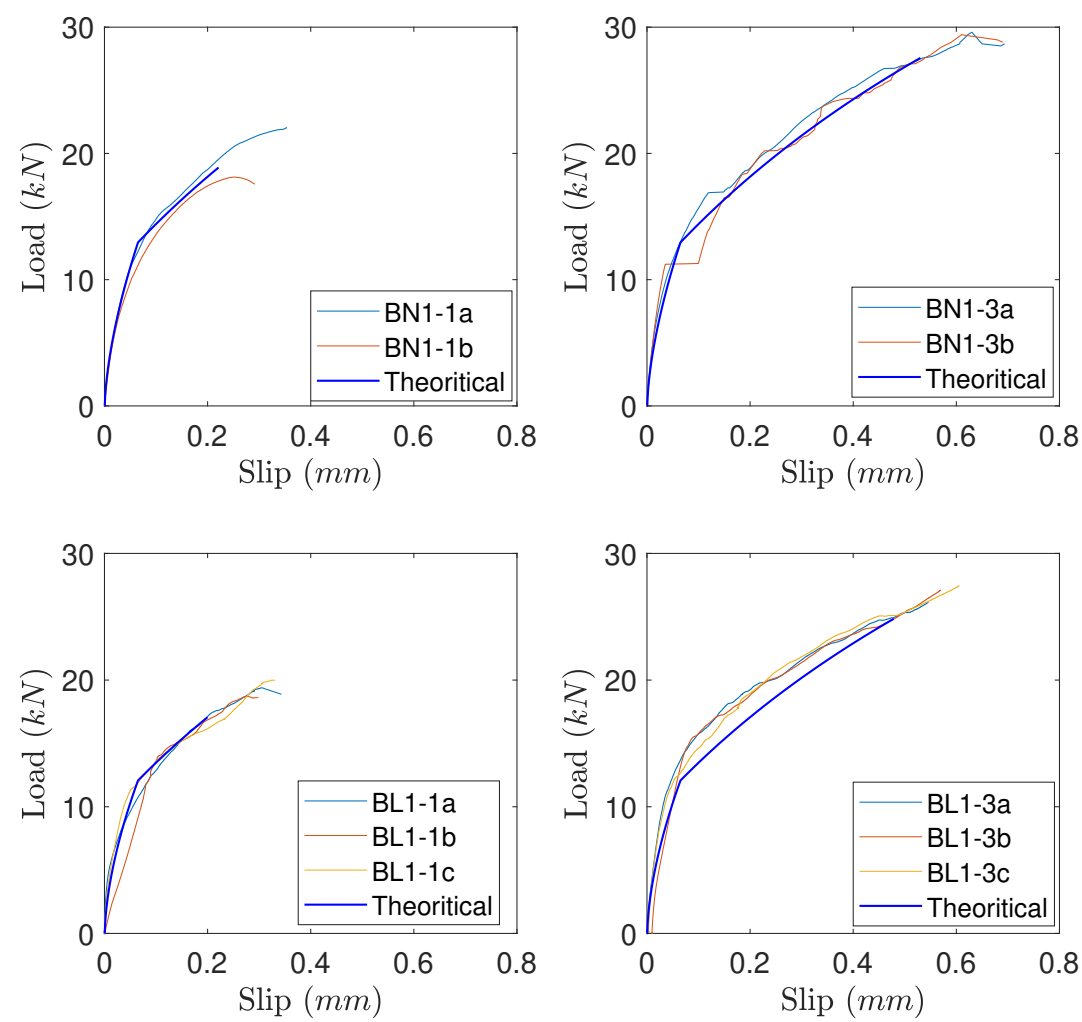

Figure 11: Comparison of load-slip curves (a) BN1-1, (b) BN1-3, (c) BL1-1 and (d) BL1-3 

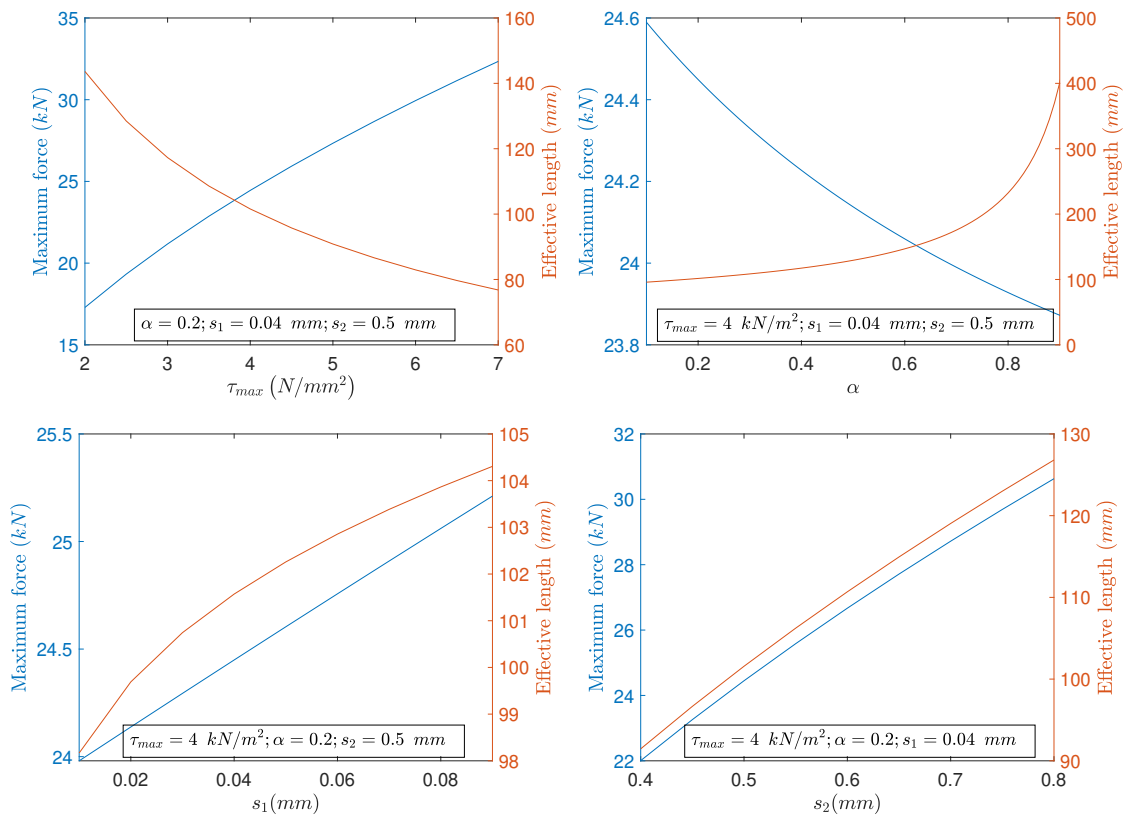

Figure 12: Sensitivity of bond stress-slip model parameters: (a) $\tau_{\max }$; (b) $\alpha$; (c) $s_{1}$ and (d) $s_{2}$. Al-Allaf et al's 17 normal concrete properties and physical dimensions (Tables 2 and 3 , are used for this sensitivity study.

strength $\left(\tau_{\max }\right)$ and $s_{2}$ significantly alter the maximum resisting force compared to $\alpha$ and $s_{1}$. Also, effective bond length is significantly increased when the parameter $\alpha$ is more than 0.8 .

\subsection{Material and geometric characteristic of test set up}

Figure 13 (a) shows the effect of the concrete strength on the maximum bond strength and effective bond length. The concrete cube compressive strength was varied from 10 to $60 \mathrm{MPa}$ in this sensitivity study. For this purpose, Lu et al's [10] bond-slip parameters were used. It should be noted that the Lu et al's bond-slip parameters are based on the tensile strength of the concrete.

Figure 13 (b) shows the effect of FRP thickness on the maximum bond strength and effective bond length. The stiffness of the FRP composite is defined as the laminate thickness's multiplied by FRP elastic modulus $\left(t_{f} E_{f}\right)$. For this, 



Figure 13: Bond-slip parameters obtained from Lu et al's (2005) model are used. Al-Allaf et al's normal concrete and physical dimensions of the test set-up are used. (a) Concrete cube strength (b) FRP thickness.

the FRP thickness was varied. It can be observed that as the stiffness of the sheet increases, the maximum bond strength increases. This may be attributed to the fact that the thicker FRP reinforcement has higher axial rigidity and therefore provides higher resistance.

\section{Conclusion}

An analytical method for determination of the inter-facial behaviour in FRPto-concrete bonded joints has been proposed in this study. The model was developed based on a non-linear bond shear stress-slip relationship in the primary zone and linear bond shear stress-slip relationship in the secondary zone. The main characteristics of the bond (load-slip curve and bond stress and strain profiles along the FRP) were derived using concrete and FRP materials, and geometries of test specimen and FRP and load set-up. This analytical model is superior to any semi-empirical derivation of effective length and maximum force, which were commonly reported in the literature, as this model allows the understanding of the all the aspects of the bond between FRP and concrete. Also, the theoretical derivation can be extended to most of the linear and/or bi-linear bond-slip models reported in the literature. Furthermore, the proposed model introduces the confined and unconfined concrete through single and dou- 
ble lap shear tests, which were not discussed in any models reported in the literature. Thus, the theoretically vigorous derivation can be applied to most of the practical situations encountered for bond-slip between FRP and concrete.

\section{References}

[1] B. Täljsten, Defining anchor lengths of steel and CFRP plates bonded to concrete, International Journal of Adhesion and Adhesives 17 (4) (1997) 319-327.

[2] A. Cottone, G. Giambanco, Minimum bond length and size effects in FRP-substrate bonded joints, Engineering Fracture Mechanics 76 (13) (2009) 1957-1976.

[3] R. Al-Rousan, M. Issa, Fatigue performance of reinforced concrete beams strengthened with CFRP sheets, Construction and Building Materials 25 (8) (2011) 3520-3529.

[4] C. Pellegrino, D. Tinazzi, C. Modena, Experimental study on bond behavior between concrete and FRP reinforcement, Journal of Composites for Construction 12 (2) (2008) 180-189.

[5] A. Khalifa, W. J. Gold, A. Nanni, A. A. MI, Contribution of externally bonded FRP to shear capacity of RC flexural members, Journal of composites for construction 2 (4) (1998) 195-202.

[6] D. Van Gemert, Force transfer in epoxy bonded steel/concrete joints, International Journal of Adhesion and Adhesives 1 (2) (1980) 67-72.

[7] J. F. Chen, J. G. Teng, Anchorage strength models for FRP and steel plates bonded to concrete, Journal of structural engineering 127 (7) (2001) 784-791.

[8] K. Nakaba, T. Kanakubo, T. Furuta, H. Yoshizawa, Bond behavior between fiber-reinforced polymer laminates and concrete, Structural Journal 98 (3) (2001) 359-367. 
[9] G. Monti, M. Renzelli, P. Luciani, FRP adhesion in uncracked and cracked concrete zones, in: Fibre-Reinforced Polymer Reinforcement for Concrete Structures: (In 2 Volumes), World Scientific, 2003, pp. 183-192.

[10] X. Z. Lu, J. G. Teng, L. P. Ye, J. J. Jiang, Bond-slip models for FRP sheets/plates bonded to concrete, Engineering Structures 27 (6) (2005) 920-937. doi:10.1016/j.engstruct.2005.01.014.

[11] Y. F. Wu, X. S. Xu, J. B. Sun, C. Jiang, Analytical solution for the bond strength of externally bonded reinforcement, Composite Structures 94 (11) (2012) 3232-3239. doi:10.1016/j.compstruct.2012.04.026. URL http://dx.doi.org/10.1016/j.compstruct.2012.04.026

[12] Z. Ouyang, B. Wan, An analytical model of FRP-concrete bond deterioration in moist environment, Advances in Structural Engineering 12 (6) (2009) 761-769. doi:10.1260/136943309790327680.

[13] J. Wang, Cohesive zone model of FRP-concrete interface debonding under mixed-mode loading, International Journal of Solids and Structures 44 (20) (2007) 6551-6568. doi:10.1016/j.ijsolstr.2007.02.042.

[14] N. Valoroso, S. de Barros, Adhesive joint computations using cohe$\square$ sive zones, Applied Adhesion Science 1 (1) (2013) 1-9. doi:10.1186/ 2196-4351-1-8.

[15] J. Dai, T. Ueda, Y. Sato, Development of the Nonlinear Bond Stress-Slip Model of Fiber Reinforced Plastics Sheet-Concrete Interfaces with a Simple Method, Journal of Composites for Construction 9 (1) (2005) 52-62. doi: 10.1061/(asce) 1090-0268(2005)9:1(52).

[16] Y. W. Zhou, Y. F. Wu, Y. Yun, Analytical modeling of the bond-slip relationship at FRP-concrete interfaces for adhesively-bonded joints, Com1 posites Part B: Engineering 41 (6) (2010) 423-433. doi:10.1016/j. 325 compositesb.2010.06.004. URL http://dx.doi.org/10.1016/j.compositesb.2010.06.004 
[17] M. H. Al-Allaf, L. Weekes, L. Augusthus-Nelson, P. Leach, An experimental

n investigation into the bond-slip behaviour between CFRP composite and lightweight concrete, Construction and Building Materials 113 (2016) 15-

33027 . doi:10.1016/j.conbuildmat.2016.03.032.

URL http://dx.doi.org/10.1016/j.conbuildmat.2016.03.032

[18] M. Baena, L. Torres, A. Turon, M. Llorens, C. Barris, Bond behaviour between recycled aggregate concrete and glass fibre reinforced polymer bars, Construction and Building Materials 106 (2016) 449-460.

335 [19] R. H. Haddad, R. Al-Rousan, A. Almasry, Bond-slip behavior between carbon fiber reinforced polymer sheets and heat-damaged concrete, Composites Part B: Engineering 45 (1) (2013) 1049-1060.

[20] M. H. Al-Allaf, L. Weekes, L. Augusthus-Nelson, Shear behaviour of lightweight concrete beams strengthened with CFRP composite, Magazine of Concrete Research 71 (18) (2019) 949-964. doi:10.1680/jmacr.17. 00488

[21] D. Fernando, J.-G. Teng, T. Yu, X.-L. Zhao, Preparation and characterization of steel surfaces for adhesive bonding, Journal of Composites for Construction 17 (6) (2013) 4013012.

[22] I. Iovinella, A. Prota, C. Mazzotti, Influence of surface roughness on the bond of FRP laminates to concrete, Construction and Building Materials 40 (2013) 533-542.

[23] D. Mostofinejad, E. Mahmoudabadi, Grooving as alternative method of surface preparation to postpone debonding of FRP laminates in concrete beams, Journal of Composites for Construction 14 (6) (2010) 804-811.

[24] Z. Wu, X. Wang, K. Iwashita, T. Sasaki, Y. Hamaguchi, Tensile fatigue behaviour of FRP and hybrid FRP sheets, Composites Part B: Engineering 41 (5) (2010) 396-402. 
[25] F. Ceroni, E. Cosenza, M. Gaetano, M. Pecce, Durability issues of FRP rebars in reinforced concrete members, Cement and concrete composites 28 (10) (2006) 857-868.

[26] M. Mahal, B. Täljsten, T. Blanksvärd, Experimental performance of RC beams strengthened with FRP materials under monotonic and fatigue loads, Construction and Building Materials 122 (2016) 126-139.

[27] A. Ahmed, V. K. R. Kodur, Effect of bond degradation on fire resistance of FRP-strengthened reinforced concrete beams, Composites Part B: Engineering 42 (2) (2011) 226-237.

[28] M. A. G. Silva, H. Biscaia, Degradation of bond between FRP and RC beams, Composite structures 85 (2) (2008) 164-174.

[29] M. Leone, S. Matthys, M. A. Aiello, Effect of elevated service temperature on bond between FRP EBR systems and concrete, Composites Part B: Engineering 40 (1) (2009) 85-93.

[30] S. J. Foster, N. Khomwan, Determination of bond stress versus slip for externally bonded FRP from standardized bond strength tests, in: Proceedings of the International Symposium on Bond Behaviour of FRP in Structures (BBFS 2005), 2005.

[31] H. Yuan, J. G. Teng, R. Seracino, Z. S. Wu, J. Yao, Full-range behavior of FRP-to-concrete bonded joints, Engineering structures 26 (5) (2004) 553565.

[32] Y. F. Wu, C. Jiang, Quantification of bond-slip relationship for externally bonded FRP-to-concrete joints, Journal of Composites for Construction 17 (5) (2013) 673-686. doi:10.1061/(ASCE)CC.1943-5614.0000375.

[33] A. D. Polyanin, V. F. Zaitsev, Handbook of nonlinear partial differential equations, Chapman and Hall/CRC, 2016. 
390

[37] A. Serbescu, M. Guadagnini, K. Pilakoutas, Standardised double-shear n. test for determining bond of FRP to concrete and corresponding model п development, Composites Part B: Engineering 55 (2013) 277-297. doi:

[34] Z. Wu, S. M. Islam, H. Said, A three-parameter bond strength model for FRP-concrete interface, Journal of Reinforced Plastics and Composites 28 (19) (2009) 2309-2323. doi:10.1177/0731684408091961.

[35] A. Bilotta, F. Ceroni, M. Di Ludovico, E. Nigro, M. Pecce, G. Manfredi, Bond efficiency of EBR and NSM FRP systems for strengthening concrete members, Journal of Composites for Construction 15 (5) (2011) 757-772. doi:10.1061/(ASCE)CC.1943-5614.0000204

[36] A. Bilotta, M. D. Ludovico, E. Nigro, FRP-to-concrete interface debonding: Experimental calibration of a capacity model, Composites Part B: Engineering 42 (6) (2011) 1539-1553. doi:10.1016/j.compositesb.2011.04. 016.

URL http://dx.doi.org/10.1016/j.compositesb.2011.04.016 10.1016/j.compositesb.2013.06.019.

URL http://dx.doi.org/10.1016/j.compositesb.2013.06.019

[38] L. Bizindavyi, K. W. Neale, Transfer lengths and bond strengths for composites bonded to concrete, Journal of composites for construction 3 (4) (1999) 153-160.

[39] Z. Tan, Experimental research for RC beam strengthened with GFRP, Graduation thesis, Tsinghua Univ., Beijing, China (in Chinese) (2002).

[40] H. D. Zhao, Y. Zhang, M. Zhao, Research on the bond performance between CFRP plate and concrete, in: Proc., 1st Conf. on FRP Concrete Structures of China, 2000, pp. 247-253.

[41] K. Takeo, H. Matsushita, T. Makizumi, G. Nagashima, Bond characteristics of CFRP sheets in the CFRP bonding technique, Proceedings of Japan concrete institute 19 (2) (1997) 1599-1604. 
[42] H. T. Ren, Study on basic theories and long time behavior of concrete structures strengthened by fiber reinforced polymers, Dalian University of technology (2003).

[43] T. Ueda, Y. Sato, Y. Asano, Experimental study on bond strength of continuous carbon fiber sheet, Special Publication 188 (1999) 407-416.

[44] Z. Wu, H. Yuan, H. Yoshizawa, T. Kanakubo, Experimental/analytical study on interfacial fracture energy and fracture propagation along frpconcrete i nterface, Special Publication 201 (2001) 133-152.

[45] H. Toutanji, P. Saxena, L. Zhao, T. Ooi, Prediction of interfacial bond failure of FRP-concrete surface, Journal of composites for construction 11 (4) (2007) 427-436.

[46] J. Yao, J. G. Teng, J. F. Chen, Experimental study on FRP-to-concrete bonded joints, Composites Part B: Engineering 36 (2) (2005) 99-113. doi: $10.1016 / j . c o m p o s i t e s b .2004 .06 .001$.

[47] M. J. Chajes, W. W. Finch, T. A. Thomson, Bond and force transfer of composite-material plates bonded to concrete, Structural Journal 93 (2) (1996) 209-217.

[48] M. H. Al-Allaf, L. Weekes, L. Augusthus-Nelson, Experimental study on bond-slip behaviour between CFRP sheets and lightweight concrete, in: Advanced Composites in Construction, ACIC 2015 - Proceedings of the 7th Biennial Conference on Advanced Composites In Construction, 2015, pp. $122-127$.

[49] U. Neubauer, F. S. Rostasy, Bond failure of concrete fiber reinforced polymer plates at inclined cracks - experiments and fracture mechanics model, Special publication 188 (1999) 369-382.

[50] M. Savoia, B. Ferracuti, C. Mazzotti, Non linear bond-slip law for FRPconcrete interface, in: Fibre-Reinforced Polymer Reinforcement for Concrete Structures: (In 2 Volumes), World Scientific, 2003, pp. 163-172. 